\title{
Clinical behavior and outcomes of breast cancer in young women with germline $B R C A$ pathogenic variants
}

\author{
Matteo Lambertini ${ }^{1,2 凶}{ }^{1,}$, Marcello Ceppi ${ }^{3}$, Anne-Sophie Hamy (D) $^{4}$, Olivier Caron (D) $^{5}$, Philip D. Poorvu ${ }^{6}$, Estela Carrasco ${ }^{7}$, \\ Albert Grinshpun $\left(\mathbb{D}^{8}\right.$, Kevin Punie (iD $^{9}$, Christine Rousset-Jablonski (D) $^{10}$, Alberta Ferrari (iD ${ }^{11}$, Shani Paluch-Shimon ${ }^{12}$, Angela Toss ${ }^{13}$, \\ Claire Senechal ${ }^{14}$, Fabio Puglisi $\mathbb{D D}^{15,16}$, Katarzyna Pogoda ${ }^{17}$, Jose Alejandro Pérez-Fidalgo ${ }^{18}$, Laura De Marchis ${ }^{19}$, Riccardo Ponzone $\mathbb{D}^{20}{ }^{20}$ \\ Luca Livraghi $\mathbb{D}^{21,22}$, Maria Del Pilar Estevez-Diz $\mathbb{D i D}^{23}$, Cynthia Villarreal-Garza $\mathbb{1}^{24,25}$, Maria Vittoria Dieci $\mathbb{( i D}^{26,27}$, Florian Clatot ${ }^{28}$, \\ Francois P. Duhoux (D) $^{29}$, Rossella Graffeo ${ }^{30}$, Luis Teixeira ${ }^{31}$, Octavi Córdoba $\mathbb{D}^{32}{ }^{32}$ Amir Sonnenblick ${ }^{33}$, Arlindo R. Ferreira ${ }^{34}$, \\ Ann H. Partridge $\mathbb{D}^{6}$, Antonio Di Meglio ${ }^{35}$, Claire Saule ${ }^{36}$, Fedro A. Peccatori ${ }^{37}{ }^{37}$, Marco Bruzzone (iD $^{3}$, \\ Marie Daphne $t^{\prime}$ Kint de Roodenbeke ${ }^{38}$, Lieveke Ameye ${ }^{39}$, Judith Balmaña (D), Lucia Del Mastro (iD) ${ }^{1,40,41}$ and Hatem A. Azim Jr. ${ }^{25,41}$
}

Young breast cancer $(B C)$ patients carrying a germline $B R C A$ pathogenic variant ( $m B R C A)$ have similar outcomes as non-carriers. However, the impact of the type of gene (BRCA1 vs. BRCA2) and hormone receptor status (positive [HR+] vs. negative [HR-]) on clinical behavior and outcomes of $m B R C A B C$ remains largely unknown. This is an international, multicenter, hospital-based, retrospective cohort study that included $m B R C A$ patients diagnosed, between January 2000 and December 2012, with stage I-III invasive early $B C$ at age $\leq 40$ years. From 30 centers worldwide, 1236 young $m B R C A B C$ patients were included. Among 808 and 428 patients with $m B R C A 1$ or $m B R C A 2,191(23.6 \%)$ and $356(83.2 \%)$ had HR+tumors, respectively $(P<0.001)$. Median follow-up was 7.9 years. Second primary $B C(P=0.009)$ and non-BC malignancies $(P=0.02)$ were more frequent among $m B R C A 1$ patients while distant recurrences were less frequent $(P=0.02)$. Irrespective of hormone receptor status, $m B R C A 1$ patients had worse disease-free survival (DFS; adjusted $\mathrm{HR}=0.76,95 \% \mathrm{Cl}=0.60-0.96)$, with no difference in distant recurrence-free interval (DRFI) and overall survival (OS). Patients with HR+ disease had more frequent distant recurrences $(P<0.001)$ and less frequent second primary malignancies (BC: $P=0.005$; non-BC: $P=0.18$ ). No differences in DFS and OS were observed according to hormone receptor status, with a tendency for worse DRFI (adjusted $\mathrm{HR}=1.39,95 \% \mathrm{Cl}=0.94-2.05$ ) in patients with $\mathrm{HR}+\mathrm{BC}$. Type of $m B R C A$ gene and hormone receptor status strongly impact $B C$ clinical behavior and outcomes in $M B R C A$ young patients. These results provide important information for patients' counseling on treatment, prevention, and surveillance strategies.

npj Breast Cancer (2021)7:16; https://doi.org/10.1038/s41523-021-00224-w

\section{INTRODUCTION}

In women aged $\leq 40$ years, breast cancer is the most common malignancy and the first cause of cancer-related mortality ${ }^{1}$. Despite the higher risk of developing triple-negative and HER2-positive breast cancer, the majority of breast malignancies arising in young patients are hormone receptor-positive tumors ${ }^{2}$. In young patients, the prognosis for hormone receptor-positive breast cancers is worse when compared to their older counterparts ${ }^{3}$.

\footnotetext{
'Department of Internal Medicine and Medical Specialties (DIMI), School of Medicine, University of Genova, Genova, Italy. ${ }^{2}$ Department of Medical Oncology, U.O.C, Clinica di Oncologia Medica, IRCCS Ospedale Policlinico San Martino, Genova, Italy. ${ }^{3}$ Clinical Epidemiology Unit, IRCCS Ospedale Policlinico San Martino, Genova, Italy. ${ }^{4}$ Department of Medical Oncology, Institut Curie, Paris, France. ${ }^{5}$ Department of Medical Oncology, Institut Gustave Roussy, Université Paris-Saclay, Villejuif, France. ${ }^{6}$ Department of Medical Oncology, Dana-Farber Cancer Institute, Boston, MA, USA. ${ }^{7}$ Hereditary Cancer Genetics Group, Vall d'Hebron Institute of Oncology (VHIO), Hospital Universitari Vall d'Hebron Barcelona Hospital Campus, Barcelona, Spain. ${ }^{8}$ Sharett Institute of Oncology, Hadassah-Hebrew University Medical Center, Jerusalem, Israel. ${ }^{9}$ Department of General Medical Oncology and Multidisciplinary Breast Centre, Leuven Cancer Institute, University Hospitals Leuven, Leuven, Belgium. ${ }^{10}$ Department of Surgery, Centre Léon Bérard, Lyon, France. ${ }^{11}$ Department of Surgical Sciences, General Surgery III - Breast Surgery, Fondazione IRCCS Policlinico San Matteo, University of Pavia, aBRCAdaBRA onlus, Pavia, Italy. ${ }^{12}$ Breast Oncology Unit, Shaare Zedek Medical Centre and Department of Oncology, Sheba Medical Center, Tel Hashomer, Jerusalem, Israel. ${ }^{13}$ Department of Oncology and Haematology, Azienda Ospedaliero-Universitaria Policlinico di Modena, Modena, Italy. ${ }^{14}$ Cancer Genetics Unit, Bergonie Institute, Bordeaux, France. ${ }^{15}$ Department of Medical Oncology, Centro di Riferimento Oncologico di Aviano (CRO) IRCCS, Aviano, Italy. ${ }^{16}$ Department of Medicine, University of Udine, Udine, Italy. ${ }^{17}$ Department of Breast Cancer and Reconstructive Surgery, Maria Sklodowska-Curie National Research Institute of Oncology, Warsaw, Poland. ${ }^{18}$ Department of Medical Oncology, INCLIVA University Hospital of Valencia, CIBERONC, Valencia, Spain. ${ }^{19}$ Division of Medical Oncology, Department of Radiological, Oncological and Pathological Sciences, "La Sapienza" University of Rome, Rome, Italy. ${ }^{20}$ Gynecological Oncology, Candiolo Cancer Institute, FPO - IRCCS, Candiolo, Turin, Italy. ${ }^{21}$ Medical Oncology Unit, ASST Papa Giovanni XXIII, Bergamo, Italy. ${ }^{22}$ University of Siena, Siena, Italy. ${ }^{23}$ Departament of Oncology, Instituto do Cancer do Estado de Sao Paulo - Faculdade de Medicina da Universidade de Sao Paulo, Pacaembu, Sao Paulo, Brazil. ${ }^{24}$ Department of Research and Breast Tumors, Mexican National Cancer Institute, Mexico City, Mexico. ${ }^{25}$ Breast Cancer Center, Hospital Zambrano Hellion, Tecnologico de Monterrey, San Pedro Garza Garcia, NL, Mexico. ${ }^{26}$ Department of Surgery, Oncology and Gastroenterology, University of Padua, Padua, Italy. ${ }^{27}$ Medical Oncology 2 , Veneto Institute of Oncology IOV - IRCCS, Padua, Italy. ${ }^{28}$ Department of Medical Oncology, Centre Henri Becquerel, Rouen, France. ${ }^{29}$ Department of Medical Oncology, Breast Clinic, Cliniques Universitaires Saint-Luc, UCLouvain, Brussels, Belgium. ${ }^{30}$ Breast Unit of Southern Switzerland (CSSI), Oncology Institute of Southern Switzerland, Bellinzona, Switzerland. ${ }^{31}$ Breast Disease Unit, Saint-Louis Hospital, APHP, Université de Paris, INSERM U976, Paris, France. ${ }^{32}$ Obstetrics and Gynecology Department, Hospital Universitari Son Espases, Palma, Spain. ${ }^{33}$ Oncology Division, Tel Aviv Sourasky Medical Center and Sackler Faculty of Medicine, Tel Aviv, Israel. ${ }^{34}$ Breast Unit, Champalimaud Clinical Center, Champalimaud Foundation, Lisbon, Portugal. ${ }^{35}$ Predictive Biomarkers and New Therapeutic Strategies in Oncology, INSERM Unit 981, Gustave Roussy, Villejuif, France. ${ }^{36}$ Department of Genetics, Institut Curie, Paris, France. ${ }^{37}$ Gynecologic Oncology Department, European Institute of Oncology IRCCS, Milan, Italy. ${ }^{38}$ Department of Medicine, Institut Jules Bordet and Université Libre de Bruxelles (U.L.B.), Brussels, Belgium. ${ }^{39}$ Data Centre, Institut Jules Bordet and Université Libre de Bruxelles (U.L.B.), Brussels, Belgium. ${ }^{40}$ Breast Unit, IRCCS Ospedale Policlinico San Martino, Genova, Italy. ${ }^{41}$ These authors contributed equally: Lucia Del Mastro, Hatem A. Azim Jr. ${ }^{\bowtie}$ email: matteo.lambertini@unige.it
} 
Other age-related issues should be considered in the management of breast cancer in young women ${ }^{4}$. Among them, genetic counseling and testing is key. Approximately $12 \%$ of cases arising in women aged $\leq 40$ years are related to germline pathogenic variants in $B R C A 1$ or $B R C A 2^{5,6}$. Indeed, young age at diagnosis is a criterion to refer patients to genetic counseling irrespective of family history or other tumor biological features ${ }^{4}$. Identification of a germline pathogenic variant in the $B R C A$ genes plays a crucial role in cancer prevention and treatment ${ }^{7,8}$. BRCA-related breast cancers have distinct biological features, including a tendency for hormone receptor-negativity in BRCA1 carriers and hormone receptor positivity in $B R C A 2$ carriers $^{9-12}$.

Several studies have investigated the prognostic role of carrying germline BRCA pathogenic variants ${ }^{13}$. Compared to women with sporadic breast cancer, current evidence does not support different outcomes in those with BRCA pathogenic variants ${ }^{13}$. Similarly, no difference in survival outcomes between young breast cancer patients with or without germline BRCA pathogenic variants have been shown, except a trend for a survival advantage in BRCA-mutated patients with triple-negative breast cancer compared with non-carriers ${ }^{6}$. Nevertheless, besides the known differences in clinicopathological features in breast cancer cases associated with germline BRCA1 or BRCA2 pathogenic variants ${ }^{9-12}$, there is a lack of evidence so far on whether the type of mutated gene may also lead to potential differences in breast cancer clinical behavior and outcomes. In addition, the prognostic value of hormone receptor status in BRCA-related breast cancers remains largely unknown. We addressed these important issues in a large series of young breast cancer patients harboring germline $B R C A$ pathogenic variants.

\section{RESULTS}

\section{Study cohort}

Out of 1424 patients registered in the study from 30 centers worldwide, 1236 young BRCA-mutated breast cancer patients were eligible for inclusion in the present analysis (Supplementary Fig. 1).

Among 808 and 428 patients with germline BRCA1 and BRCA2 pathogenic variants, 191 (23.6\%) and $356(83.2 \%)$ had hormone receptor-positive tumors, respectively $(P<0.001)$.

\section{Comparison between patients with germline BRCA1 and BRCA2 pathogenic variants}

Compared to patients in the BRCA2 cohort, those in the BRCA1 cohort were younger, more likely to have Israeli origin, had more grade 3 tumors, less lobular histology, nodal involvement, and HER2-positive disease (Table 1). Women in the BRCA1 cohort received chemotherapy more frequently and, among those with hormone receptor-positive disease, fewer patients received adjuvant endocrine therapy (Table 1). Although patients in the $B R C A 1$ cohort underwent breast-conserving surgery more often, no difference was observed in rates of risk-reducing mastectomy or salpingo-oophorectomy between the BRCA1 and BRCA2 cohorts, respectively (Supplementary Table 1).

Supplementary Tables 2 and 3 report the comparison in clinicopathological characteristics and risk-reducing surgery between the BRCA1 and BRCA2 cohorts according to hormone receptor status.

Median follow-up was 7.9 years (interquartile range 5.6-10.6 years), with no difference between the BRCA1 and BRCA2 cohorts $(P=0.95)$. In terms of the first DFS event, second primary malignancies (breast cancer: $17.0 \%$ vs. $12.2 \%, P=0.009$; nonbreast cancer: $4.3 \%$ vs. $1.9 \%, P=0.02$ ) were more frequent in the $B R C A 1$ cohort while distant recurrences were less frequent $(10.4 \%$ vs. $15.4 \%, P=0.02$ ) as compared to the BRCA2 cohort (Table 2 ). When the pattern of the first DFS event was assessed between the
$B R C A 1$ and BRCA2 cohorts according to hormone receptor status, the only difference was a higher rate of second non-breast cancer primary malignancies $(5.2 \%$ vs. $1.4 \%, P=0.005)$ in the $B R C A 1$ cohort with hormone receptor-positive disease, being mostly ovarian cancer (Supplementary Table 4).

Considering DFS events, a similar pattern of annual HRs was observed between patients in the BRCA1 and BRCA2 cohorts irrespective of hormone receptor status, with a higher risk for those with BRCA1 pathogenic variants (Figs. 1a, 2a, and 3a).

Eight-year DFS was $62.8 \%$ and $65.9 \%$ in the BRCA1 and $B R C A 2$ cohorts, respectively (adjusted $\mathrm{HR}=0.76,95 \% \mathrm{Cl} 0.60-0.96$; Fig. 1b). A tendency towards worse DFS in the BRCA1 cohort was observed for both patients with hormone receptor-positive (adjusted $\mathrm{HR}=0.77,95 \% \mathrm{Cl} 0.58-1.03$; Fig. 2b) and negative (adjusted $\mathrm{HR}=0.73,95 \% \mathrm{Cl} 0.48-1.13$; Fig. 3b) breast cancer $\left(P_{\text {interaction }}=0.85\right.$; Supplementary Table 5).

Eight-year DRFI was $88.9 \%$ and $83.8 \%$ in the BRCA1 and $B R C A 2$ cohorts, respectively (adjusted $\mathrm{HR}=0.94,95 \% \mathrm{Cl} 0.64-1.38$; Fig. 1c). No significant difference in DRFI was observed for patients with either hormone receptor-positive (adjusted $\mathrm{HR}=0.94,95 \% \mathrm{Cl}$ 0.60-1.48; Fig. 2c) or negative (adjusted $\mathrm{HR}=0.92,95 \% \mathrm{Cl}$ $0.43-1.95$; Fig. $3 \mathrm{c}$ ) breast cancer $\left(P_{\text {interaction }}=0.95\right.$; Supplementary Table 6).

Eight-year OS was $86.9 \%$ and $87.5 \%$ in the BRCA1 and $B R C A 2$ cohorts, respectively (adjusted $\mathrm{HR}=0.69,95 \% \mathrm{Cl} 0.46-1.04$; Fig. $1 \mathrm{~d})$. No significant difference in OS was observed for patients with either hormone receptor-positive (adjusted $\mathrm{HR}=0.64,95 \% \mathrm{Cl}$ $0.39-1.05$; Fig. 2d) or negative (adjusted $\mathrm{HR}=0.80,95 \% \mathrm{Cl}$ $0.40-1.56$; Fig. $3 \mathrm{~d}$ ) breast cancer $\left(P_{\text {interaction }}=0.62\right.$; Supplementary Table 7).

\section{Comparison between patients with hormone receptor- positive and negative disease}

Compared to patients with hormone receptor-negative disease, those with hormone receptor-positive breast cancer were older, had less grade 3 tumors, more often lobular histology, nodal involvement, and HER2-positive disease (Supplementary Table 8). Women with hormone receptor-positive breast cancer were less likely to receive chemotherapy and underwent mastectomy more often than those with hormone receptor-negative disease (Supplementary Table 8). No differences were observed in rates of risk-reducing mastectomy and salpingo-oophorectomy between patients with hormone receptor-positive and negative breast cancer, respectively (Supplementary Table 9).

In terms of first DFS event, patients with hormone receptorpositive breast cancer had a higher incidence of distant ( \pm locoregional) recurrences $(16.1 \%$ vs. $9.0 \%, P<0.001)$ and lower incidence of second primary malignancies (breast cancer: $12.1 \%$ vs. $17.9 \%, P=0.005$; non-breast cancer: $2.8 \%$ vs. $4.0 \%, P=0.18$ ) compared to women with hormone receptor-negative disease (Table 3). A similar pattern of annual HRs was observed between patients with hormone receptor-positive and negative disease until 5 years, beyond which a rapidly increasing trend for those with hormone receptor-positive breast cancer was observed (Fig. 4a).

As reported in Supplementary Table 10, 8-year DFS was $62.9 \%$ and $64.7 \%$ in patients with hormone receptor-positive and negative disease, respectively (adjusted $\mathrm{HR}=1.06,95 \% \mathrm{Cl}$ 0.84-1.33; Fig. 4b). Eight-year DRFI was $83.4 \%$ and $90.1 \%$ in patients with hormone receptor-positive and negative disease, respectively (adjusted $\mathrm{HR}=1.39,95 \% \mathrm{Cl} 0.94-2.05$; Fig. 4c). Eightyear OS was $87.3 \%$ and $87.0 \%$ in patients with hormone receptorpositive and negative disease, respectively (adjusted $\mathrm{HR}=0.81$, 95\% Cl 0.55-1.20; Fig. 4d).

Considering that the cut-off used for defining hormone receptor positivity was not homogenous in all centers, the analyses comparing between patients with hormone receptor-positive 
Table 1. Patient, tumor and treatment characteristics.

\begin{tabular}{|c|c|c|c|}
\hline & $\begin{array}{l}\text { BRCA1 cohort } \mathrm{N}(\%) \\
n=808\end{array}$ & $\begin{array}{l}\text { BRCA2 cohort } N \\
\text { (\%) } n=428\end{array}$ & $P$ value $^{\mathrm{a}}$ \\
\hline Country & & & 0.001 \\
\hline Europe & $611(75.6)$ & $611(75.6)$ & \\
\hline North America & $52(6.4)$ & $27(6.3)$ & \\
\hline Latin America & $34(4.2)$ & $13(3.0)$ & \\
\hline Israel & $111(13.7)$ & $28(6.5)$ & \\
\hline Year at diagnosis & & & 0.33 \\
\hline 2000-2004 & $167(20.7)$ & $97(22.7)$ & \\
\hline $2005-2008$ & $304(37.6)$ & $143(33.4)$ & \\
\hline 2009-2012 & $337(41.7)$ & $188(43.9)$ & \\
\hline $\begin{array}{l}\text { Age at diagnosis, } \\
\text { median (IQR) years }\end{array}$ & $34(30-37)$ & $36(33-38)$ & $<0.001$ \\
\hline Age at diagnosis & & & $<0.001$ \\
\hline$\leq 30$ years & $206(25.5)$ & $64(15.0)$ & \\
\hline $31-35$ years & $281(34.8)$ & $143(33.4)$ & \\
\hline $36-40$ years & $321(39.7)$ & $221(51.6)$ & \\
\hline Histology & & & $<0.001$ \\
\hline Ductal carcinoma & $645(79.8)$ & $346(80.8)$ & \\
\hline Lobular carcinoma & $10(1.2)$ & $29(6.8)$ & \\
\hline Others & $87(10.8)$ & $20(4.7)$ & \\
\hline Missing & $66(8.2)$ & $33(7.7)$ & \\
\hline Tumor grade & & & $<0.001$ \\
\hline G1 & $10(1.2)$ & $13(3.0)$ & \\
\hline G2 & $110(13.6)$ & $140(32.7)$ & \\
\hline G3 & $638(79.0)$ & $251(58.6)$ & \\
\hline Missing & $50(6.2)$ & $24(5.6)$ & \\
\hline Tumor size & & & 0.95 \\
\hline $\mathrm{T} 1(\leq 2 \mathrm{~cm})$ & $331(41.0)$ & $176(41.1)$ & \\
\hline T2-T3-T4 (>2 cm) & $459(56.8)$ & $247(57.7)$ & \\
\hline Missing & $18(2.2)$ & $5(1.2)$ & \\
\hline Nodal status & & & $<0.001$ \\
\hline No & 484 (59.9) & $183(42.8)$ & \\
\hline N1-N2-N3 & $311(38.5)$ & $240(56.1)$ & \\
\hline Missing & $13(1.6)$ & $5(1.2)$ & \\
\hline $\begin{array}{l}\text { Hormone } \\
\text { receptor status }\end{array}$ & & & $<0.001$ \\
\hline $\begin{array}{l}\text { ER and/or PR } \\
\text { positive }\end{array}$ & $191(23.6)$ & $356(83.2)$ & \\
\hline$E R$ and $P R$ negative & 617 (76.4) & $72(16.8)$ & \\
\hline HER2 status & & & $<0.001$ \\
\hline HER2 negative & $760(94.1)$ & $380(88.8)$ & \\
\hline HER2 positive & $28(3.5)$ & $40(9.3)$ & \\
\hline Missing & $20(2.5)$ & $8(1.9)$ & \\
\hline Breast surgery & & & $<0.001$ \\
\hline $\begin{array}{l}\text { Breast-conserving } \\
\text { surgery }\end{array}$ & $428(53.0)$ & $158(36.9)$ & \\
\hline Mastectomy & $372(46.0)$ & $264(61.7)$ & \\
\hline Missing & $8(1.0)$ & $6(1.4)$ & \\
\hline Use of chemotherapy & & & $<0.001$ \\
\hline No & $24(3.0)$ & $33(7.7)$ & \\
\hline Yes & $782(96.8)$ & $395(92.3)$ & \\
\hline Missing & $2(0.2)$ & $0(0.0)$ & \\
\hline $\begin{array}{l}\text { Type of } \\
\text { chemotherapy }^{b}\end{array}$ & & & 0.63 \\
\hline $\begin{array}{l}\text { Anthracycline- and } \\
\text { taxane-based }\end{array}$ & $526(67.3)$ & $263(66.6)$ & \\
\hline Anthracycline-based & $196(25.1)$ & $110(27.8)$ & \\
\hline Taxane-based & $20(2.6)$ & $11(2.8)$ & \\
\hline Others & $19(2.4)$ & $6(1.5)$ & \\
\hline Missing & $21(2.7)$ & $5(1.3)$ & \\
\hline
\end{tabular}

\begin{tabular}{|c|c|c|c|}
\hline & $\begin{array}{l}\text { BRCA1 cohort } \mathrm{N}(\%) \\
n=808\end{array}$ & $\begin{array}{l}\text { BRCA2 cohort } N \\
\text { (\%) } n=428\end{array}$ & $P$ value $^{\mathrm{a}}$ \\
\hline \multicolumn{3}{|l|}{$\begin{array}{l}\text { Use of endocrine } \\
\text { therapy }^{c}\end{array}$} & $<0.001$ \\
\hline No & $28(14.7)$ & $15(4.2)$ & \\
\hline Yes & $160(83.8)$ & $339(95.2)$ & \\
\hline Missing & $3(1.6)$ & $2(0.6)$ & \\
\hline \multicolumn{3}{|l|}{$\begin{array}{l}\text { Type of endocrine } \\
\text { therapy }^{d}\end{array}$} & 0.38 \\
\hline Tamoxifen alone & $71(44.4)$ & $145(42.8)$ & \\
\hline Tamoxifen + LHRHa & 47 (29.4) & $116(34.2)$ & \\
\hline LHRHa alone & $5(3.1)$ & $3(0.9)$ & \\
\hline $\mathrm{Al} \pm \mathrm{LHRHa}$ & $7(4.4)$ & $14(4.1)$ & \\
\hline $\begin{array}{l}\text { Tamoxifen and Al } \\
?( \pm \text { LHRHa })\end{array}$ & $29(18.1)$ & $58(17.1)$ & \\
\hline Missing & $1(0.6)$ & $3(0.9)$ & \\
\hline $\begin{array}{l}\text { Duration of endocrine } \\
\text { therapy, median } \\
\text { (IQR) months }\end{array}$ & $60(28.5$ to 60$)$ & 60 (50 to 60$)$ & 0.02 \\
\hline \multicolumn{4}{|c|}{$\begin{array}{l}I Q R \text { interquartile range, } G \text { tumor grade, } T \text { tumor size, } N \text { nodal status, } E R \\
\text { estrogen receptor, } P R \text { progesterone receptor, } L H R H a \text { luteinizing hormone- } \\
\text { releasing hormone agonist, } A l \text { aromatase inhibitors. } \\
\text { aCalculated after exclusion of missing values. } \\
{ }^{b} \text { Calculated among patients who received chemotherapy. } \\
{ }^{c} \text { Calculated among patients with hormone receptor-positive breast cancer. } \\
\text { dCalculated among patients with hormone receptor-positive breast cancer } \\
\text { who received endocrine therapy. }\end{array}$} \\
\hline
\end{tabular}

and negative disease were then repeated by including only patients for whom the $1 \%$ cut-off for estrogen and/or progesterone receptor expression in their tumor was used to define hormone receptor status. Results were consistent with those reported in the main analyses (Supplementary Tables 11-14 and Supplementary Figs. 2-5).

\section{DISCUSSION}

This large unique dataset allowed an in-depth investigation of the impact of the type of mutated gene (BRCA1 vs BRCA2) and hormone receptor status on clinical behavior and outcomes of $B R C A$-mutated breast cancer in young women. We observed that patients with germline $B R C A 1$ pathogenic variants had worse DFS than those with $B R C A 2$ pathogenic variants, mainly due to higher rates of second primary malignancies (predominantly breast and ovarian cancers) irrespective of hormone receptor status, with no difference in DRFI and OS. Hormone receptor positivity was not associated with favorable prognosis in BRCA-mutated breast cancer, whatever the type of mutated gene, but rather it displayed a tendency for worse DRFI and no difference in DFS and OS compared to hormone receptor-negative disease. These data are highly relevant for counseling young BRCA-mutated breast cancer patients.

In terms of clinicopathological features, as shown in prior studies $^{9-12}$, the majority of breast cancer cases associated with germline $B R C A 1$ pathogenic variants were hormone receptornegative tumors (76\%) while those arising in BRCA2-mutated patients were hormone receptor-positive (83\%). Overall, the majority of tumors were high-grade (60-80\%) and HER2-negative (90-95\%), both features being particularly relevant in the case of BRCA1 carriers $^{9-12,14}$. In terms of clinicopathological characteristics in the $B R C A 1$ and $B R C A 2$ cohorts according to hormone receptor status, the features that remained differently distributed were country of origin and tumor grade in patients with hormone receptor-positive disease (more likely Israeli origin and high-grade tumors in the BRCA1 cohort) as well as age and HER2 status in those with hormone 
Table 2. Pattern of invasive disease-free survival events according to a type of BRCA-mutated gene.

\begin{tabular}{|c|c|c|c|}
\hline & $B R C A 1$ cohort $\mathrm{N}(\%) n=808$ & $B R C A 2$ cohort $\mathrm{N}(\%) n=428$ & $P$ value $^{\mathrm{a}}$ \\
\hline No events & $492(60.9)$ & $262(61.2)$ & 0.76 \\
\hline Distant recurrence \pm loco-regional recurrence & $84(10.4)$ & $66(15.4)$ & 0.02 \\
\hline Second primary malignancy & $35(4.3)$ & $8(1.9)$ & 0.02 \\
\hline Missing & $10(1.2)$ & $3(0.7)$ & \\
\hline Second primary breast cancer & $137(17.0)$ & $52(12.2)$ & 0.009 \\
\hline Death without any disease-free survival event & $6(0.7)$ & $4(0.9)$ & 0.79 \\
\hline
\end{tabular}

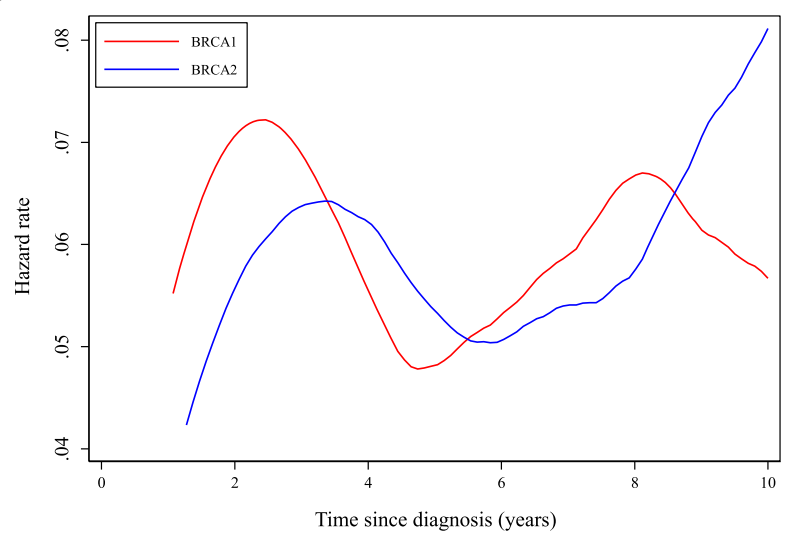

c

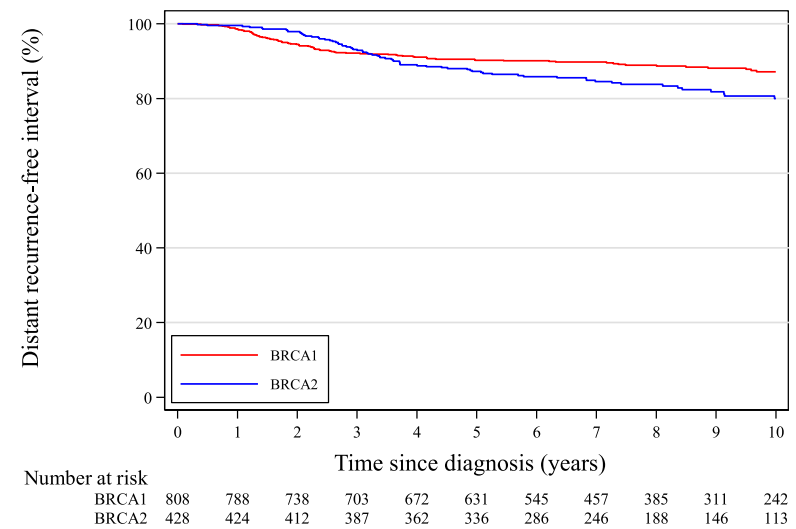

b

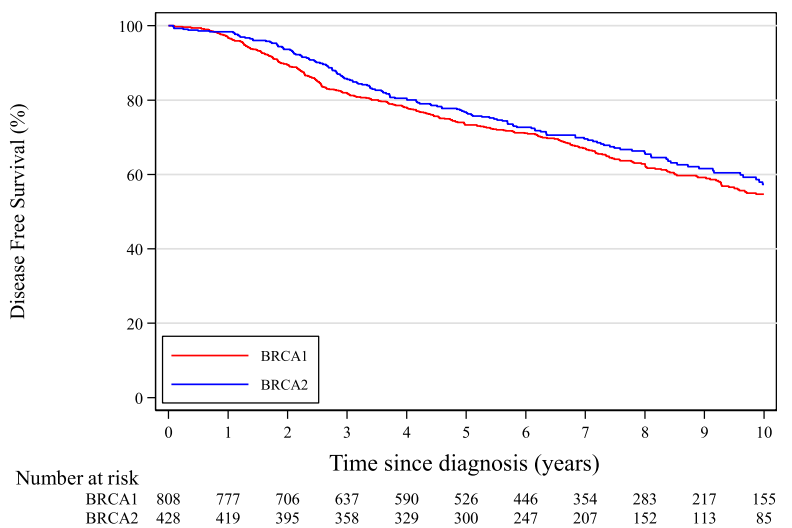

d

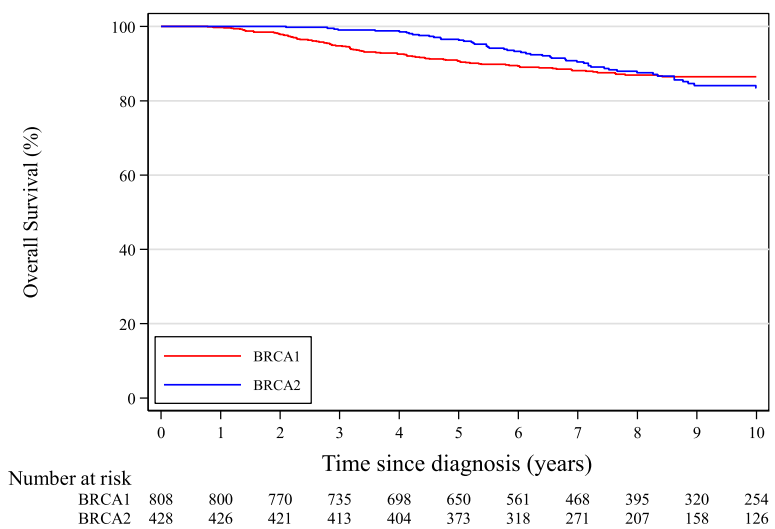

Fig. 1 Comparison between patients with germline BRCA1 and BRCA2 pathogenic variants. a Epanechnikov Kernel-Smoothed annual hazards of recurrence overall; b Disease-free survival; c Distant recurrence-free interval; d Overall survival.

receptor-negative tumors (younger age and more likely HER2negative status in the BRCA1 cohort).

Harboring a germline pathogenic variant in $B R C A 1$ or $B R C A 2$ was not previously shown to have an apparent negative prognostic impact in breast cancer ${ }^{13}$, neither in young patients ${ }^{6}$. Compared with non-carriers, a tendency for better survival outcomes in $B R C A$ carriers with triple-negative breast cancer was shown ${ }^{6}$. In addition, a reverse association of the prognostic value of hormone receptor status was observed between breast cancer patients with or without germline $B R C A$ pathogenic variants ${ }^{6,15}$, particularly in the case of $B R C A 2$ pathogenic variants ${ }^{16-18}$. Nevertheless, within the cohort of young $B R C A$-mutated breast cancer patients, the prognostic implications of carrying a germline $B R C A 1$ or $B R C A 2$ pathogenic variant as well as potential differences according to hormone receptor status remained largely undefined. Two main findings with potential clinical implications were found in our study.

Firstly, irrespective of hormone receptor status, the type of $B R C A$ gene does not appear to have prognostic value, with no observed difference in DRFI and OS between BRCA1- and BRCA2-mutated 


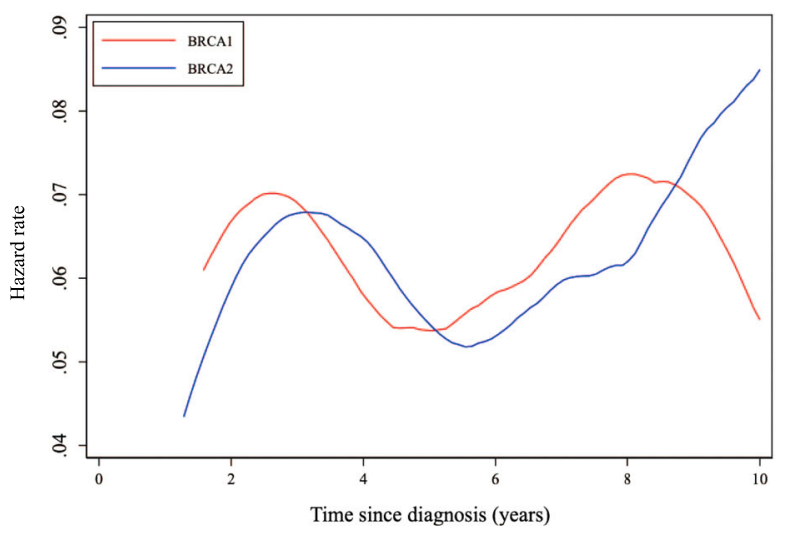

c

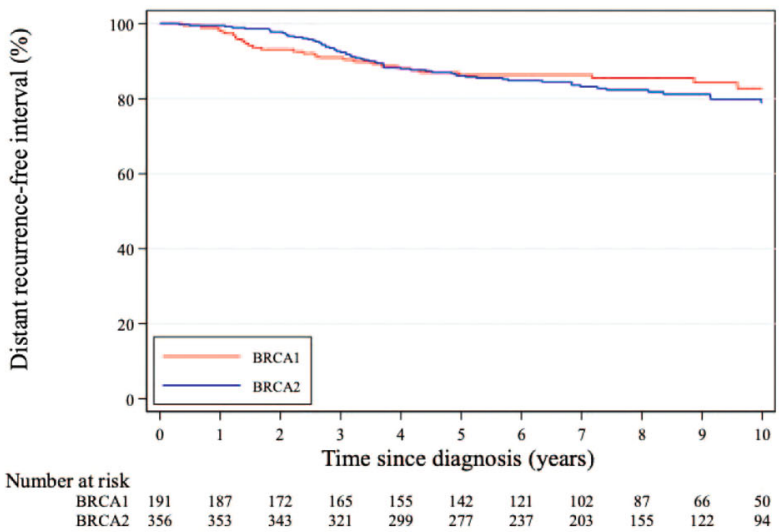

b

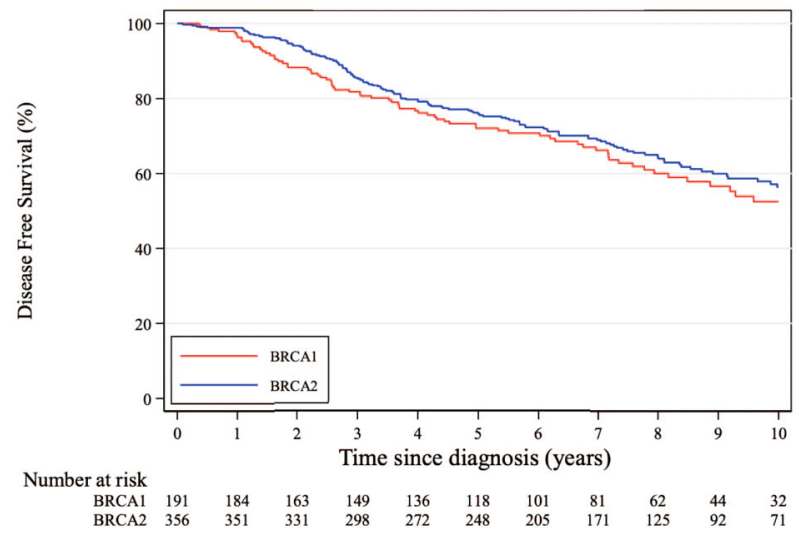

d

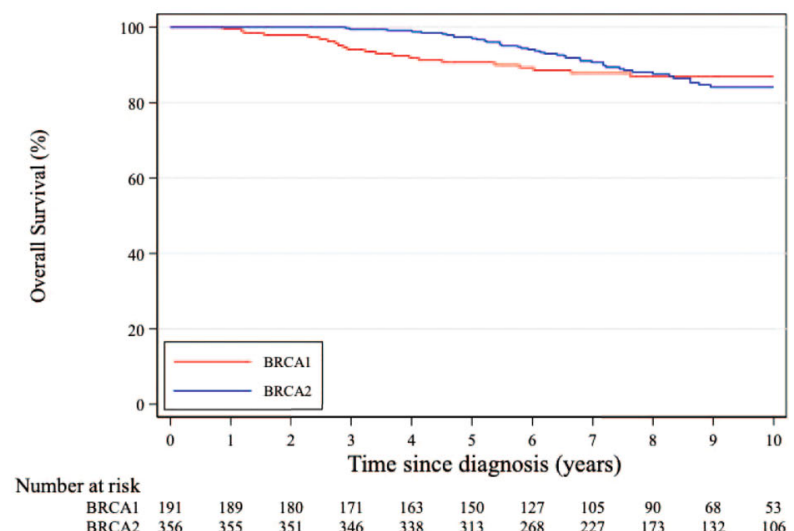

Fig. 2 Comparison between patients with germline BRCA1 and BRCA2 pathogenic variants and hormone receptor-positive disease. a Epanechnikov Kernel-Smoothed annual hazards of recurrence overall; $\mathbf{b}$ Disease-free survival; c Distant recurrence-free interval; $\mathbf{d}$ Overall survival.

patients. This is reassuring evidence for counseling young $B R C A$ mutated breast cancer patients. Nevertheless, BRCA1 carriers showed worse DFS, mostly due to higher rates of second primary malignancies (predominantly breast and ovarian cancers) as compared to BRCA2-mutated patients. This result reflects the different and age-dependent risk of cancer development associated with the two genes: the breast cancer peak of incidence occurs earlier and ovarian cancer risk is higher in $B R C A 1$ carriers as compared to those with BRCA2 pathogenic variants ${ }^{19,20}$. Young age at cancer diagnosis further increases the risk of second primary breast and ovarian malignancies ${ }^{19,21-23}$. Therefore, these findings highlight the key role of $B R C A$ genetic testing in this patient population and calls for awareness of the high risk of secondary malignancies and the option of considering riskreducing surgeries when a pathogenic variant is identified, particularly in $B R C A 1$ carriers $^{24,25}$. In addition, these results pinpoint the need to consider age-specific risk estimates when offering these procedures during patients' counseling ${ }^{23}$.

Secondly, irrespective of the type of BRCA-mutated gene, hormone receptor positivity has no favorable prognostic value in this setting. While no difference in DFS and OS was observed, patients with hormone receptor-positive breast cancer showed a higher risk of distant relapses and a trend for worse DRFI as compared to those with hormone receptor-negative disease. There are several potential explanations for this lack of prognostic advantage in young BRCA-mutated patients with hormone receptor-positive breast cancer. Estrogen signaling was shown to promote tumor initiation and progression in BRCA-deficient cells $^{26,27}$. Biological differences were reported between hormone receptor-positive breast cancers arising in patients with or without germline $B R C A$ pathogenic variants ${ }^{28,29}$. When tested with OncotypeDx, a larger proportion of $B R C A$-mutated patients were found to have high recurrence scores, and low recurrence score was not necessarily associated with low risk of recurrence ${ }^{30-32}$. Taking into account that our study included only patients $\leq 40$ years at diagnosis, these considerations may be further amplified due to the additional effect of young age on the biology of hormone-receptor-positive breast cancers ${ }^{2,3}$. Finally, it should be highlighted that $B R C A$-related tumors are known to have high chemosensitivity ${ }^{11,17,33}$, particularly in the case of hormone receptor-negative disease ${ }^{34,35}$. In our study, more than $90 \%$ of the patients received chemotherapy. However, $\sim 8 \%$ of patients with hormone receptor-positive disease did not receive adjuvant endocrine therapy, with significantly higher numbers of nonrecipients among $B R C A 1$ carriers. Although the reasons for lack of endocrine therapy administration were not collected, special attention should be paid in this regard when counseling BRCAmutated patients with hormone receptor-positive disease. Our findings provide indirect evidence to potentially consider BRCAmutated patients with hormone receptor-positive disease as a high-risk population ${ }^{36}$. Therefore, ovarian function suppression ${ }^{37}$ and extended adjuvant endocrine therapy ${ }^{38}$ may be considered relevant options in this setting. In light of the increased ovarian cancer risk, risk-reducing salpingo-oophorectomy might be considered as the primary strategy for ovarian function 
a

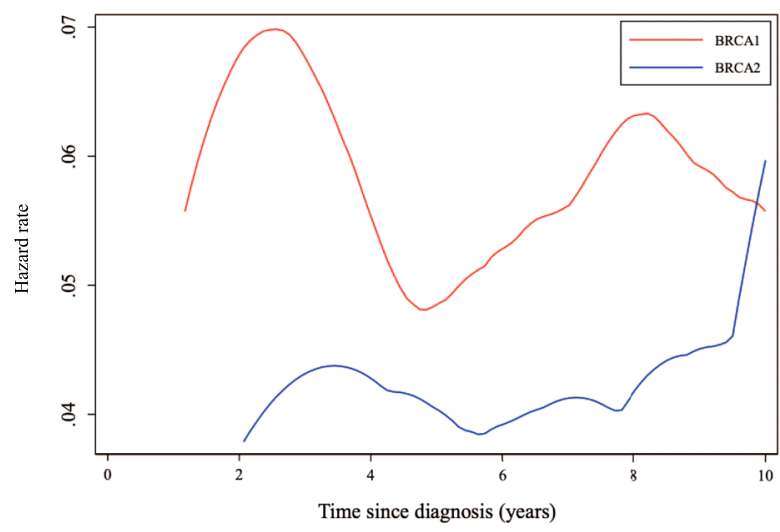

c

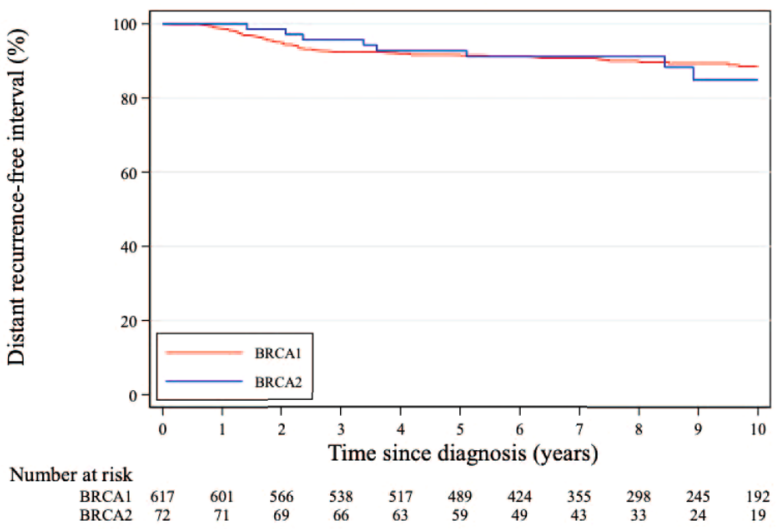

b

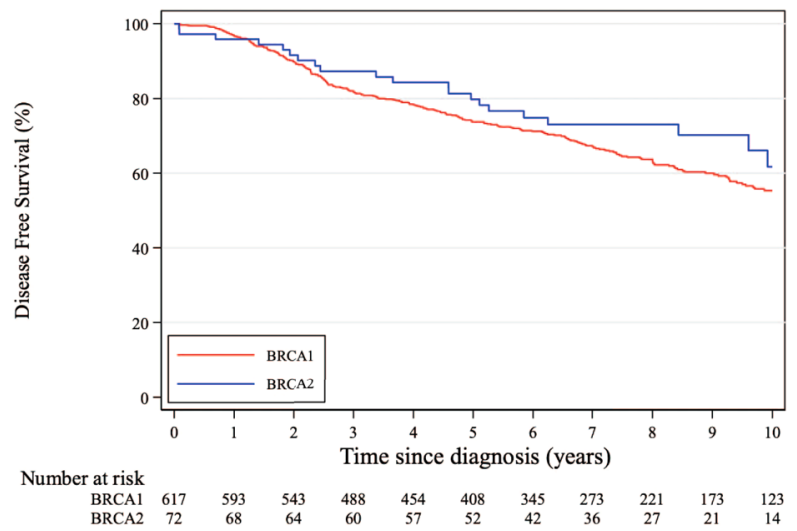

d

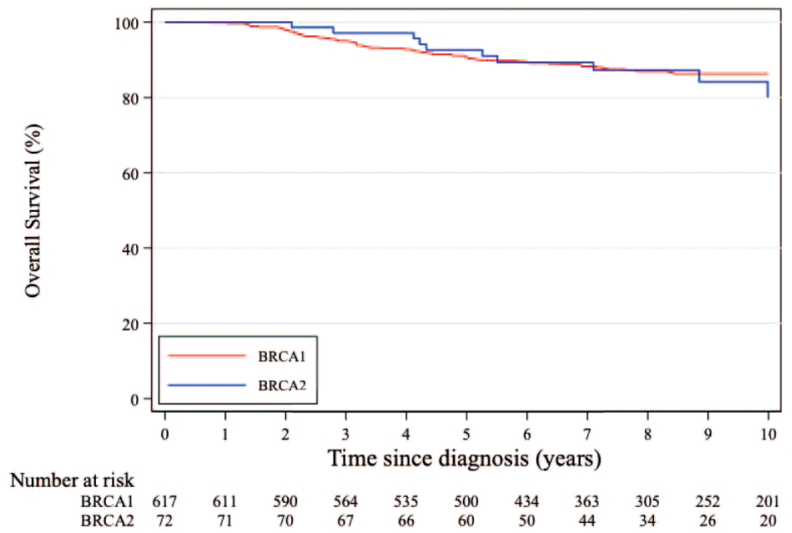

Fig. 3 Comparison between patients with germline BRCA1 and BRCA2 pathogenic variants and hormone receptor-negative disease. a Epanechnikov Kernel-Smoothed annual hazards of recurrence overall; b Disease-free survival; c Distant recurrence-free interval; d Overall survival.

Table 3. Pattern of invasive disease-free survival events according to hormone receptor status.

\begin{tabular}{llcc}
\hline & Hormone receptor-positive N (\%) $n=547$ & Hormone receptor-negative N (\%) $n=689$ & $P$ value \\
\hline Follow-up, median (IQR) & $7.8(5.8-10.6)$ & $7.9(5.5-10.6)$ & 1.00 \\
No events & $329(60.1)$ & $425(61.7)$ & 0.91 \\
Loco-regional recurrence & $45(8.2)$ & $45(6.5)$ & 0.28 \\
Distant recurrence +/- loco-regional recurrence & $88(16.1)$ & $62(9.0)$ & $28(4.0)$ \\
Second primary malignancy & $15(2.8)$ & $12(1.7)$ & $5(0.7)$ \\
Ovarian cancer & $7(1.3)$ & $11(1.6)$ \\
Other & $6(1.1)$ & $123(17.9)$ \\
Missing & $2(0.4)$ & $6(0.9)$ \\
Second primary breast cancer & $66(12.1)$ &
\end{tabular}

suppression in eligible patients who have completed their family planning.

The findings of this study should be considered in the context of its limitations. This is a retrospective cohort study conducted over a relatively long period of time. Assessment of BRCA and hormone receptor status as well as patient management were conducted according to diagnostic and treatment procedures available at that time in the respective country and center. Median follow-up was shorter than 10 years. Nevertheless, several unique features of this study should also be highlighted. This is a multicenter study, not restricted to a single continent, that included a large sample size despite focusing on a special and rare patient population (i.e., young breast cancer patients with germline BRCA pathogenic variants). The numbers of included patients and registered events made possible the acquisition of 
$\mathbf{a}$

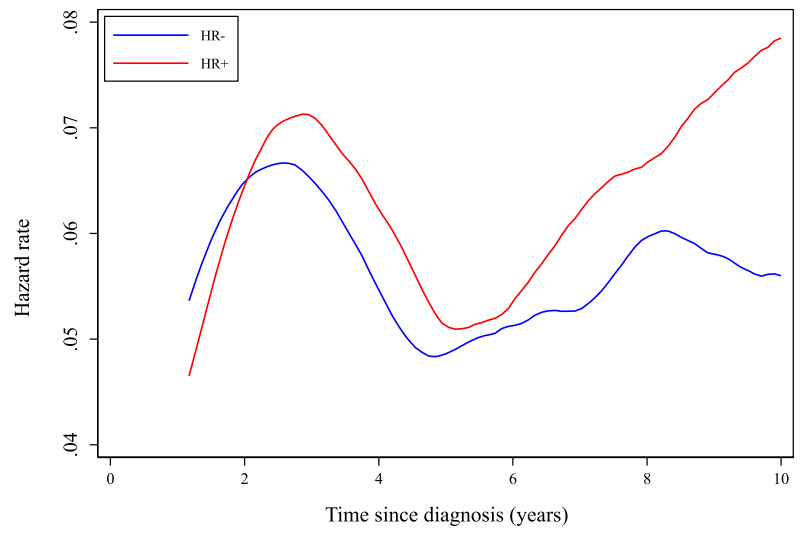

c

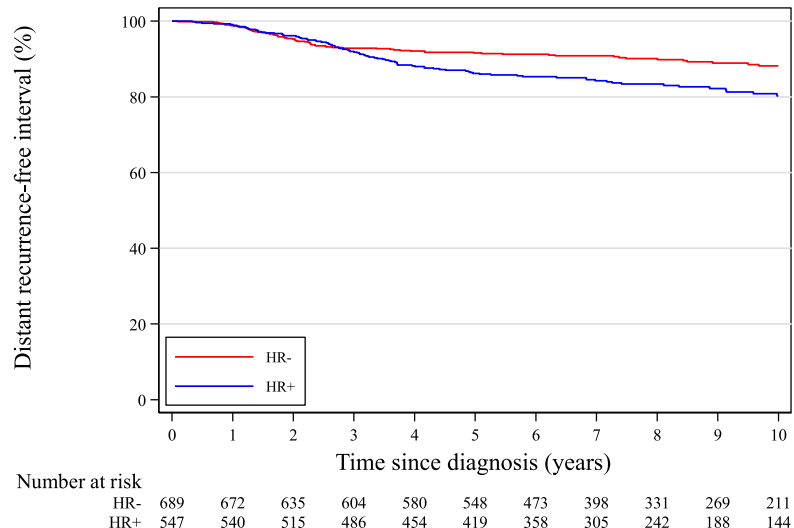

b

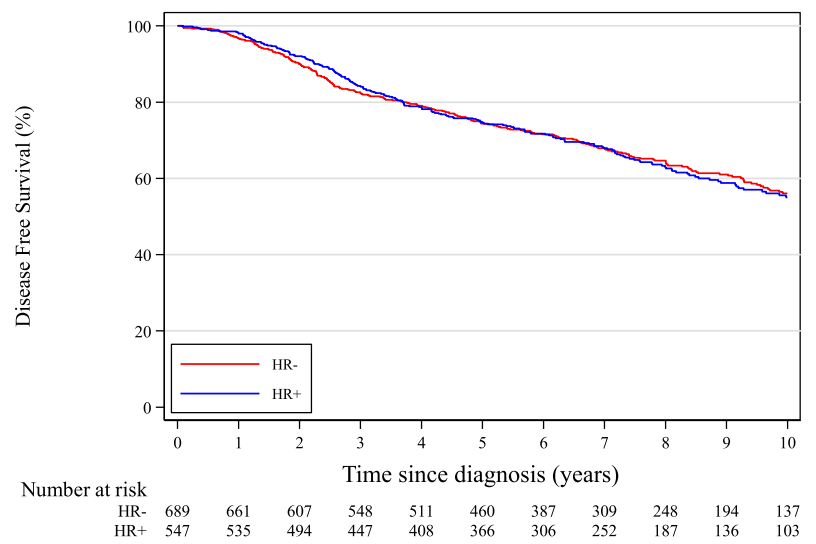

d

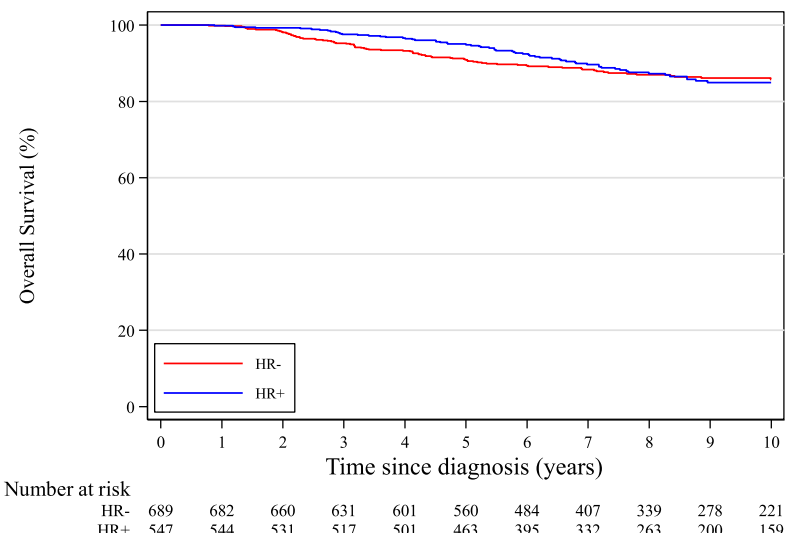

Fig. 4 Comparison between patients with hormone receptor-positive and negative disease. a Epanechnikov Kernel-Smoothed annual hazards of recurrence overall; b Disease-free survival; c Distant recurrence-free interval; d Overall survival. HR+ hormone receptor-positive; HR - hormone receptor-negative.

reliable results on these important unmet and clinically highly relevant issues.

In conclusion, type of BRCA-mutated gene and hormone receptor status strongly impact the clinical behavior and outcomes of breast cancer in young patients with germline $B R C A$ pathogenic variants. Young patients with germline $B R C A 1$ pathogenic variants had worse DFS than those with germline $B R C A 2$ pathogenic variants mostly due to higher rates of second primary malignancies irrespective of hormone receptor status. On the other hand, unlike breast cancers arising in non-BRCA carriers, hormone receptor status had no prognostic value in young $B R C A$ mutated patients, and even a tendency of worse DRFI in women with hormone receptor-positive disease was observed. These results provide important information for counseling young $B R C A$ mutated breast cancer patients regarding treatment, prevention and surveillance strategies.

\section{METHODS}

\section{Study design and participants}

Details of this study were previously reported ${ }^{39}$. Briefly, this was an international, multicenter, hospital-based, retrospective cohort study that included women diagnosed at age $\leq 40$ years with invasive early breast cancer (stage I-III) between January 2000 and December 2012. All included patients had a known germline $B R C A 1$ or $B R C A 2$ pathogenic variant.

Healthy carriers as well as women with $B R C A$ variants of uncertain significance, other malignancies (including ovarian cancer) without a prior diagnosis of invasive breast cancer, in situ or stage IV de novo breast cancer, or lack of information on follow-up were not eligible for inclusion. For the purpose of the present analysis, patients harboring pathogenic variants in both BRCA1 and BRCA2 as well as those with unknown hormone receptor status were also excluded.

Datasets from countries with more than one participating center were crosschecked to exclude potential duplicated cases.

\section{Procedures}

Data on tumor and patient characteristics, treatment, BRCA pathogenic variants, and survival outcomes were collected for all eligible patients.

The type of mutated gene was the criteria used to distinguish between two cohorts of patients: women with BRCA1 (BRCA1 cohort) and those with $B R C A 2$ (BRCA2 cohort) pathogenic variants.

$B R C A$ pathogenic variants and hormone receptor status were assessed locally at each participating center. Hormone receptor positivity was defined by the expression of estrogen and/or progesterone receptors in $\geq 1 \%$ of invasive tumor cells ( $\geq 10 \%$ in French participating centers) assessed by immunostaining.

The Institut Jules Bordet (Brussels, Belgium) coordinated the study and acted as the central ethics committee. Ethics approval by the Institutional Review Boards of participating centers and patients' written informed consent were obtained before inclusion whenever requested by local regulations.

The STrengthening the Reporting of OBservational studies in Epidemiology (STROBE) statement was followed for study reporting ${ }^{40}$.

\section{Outcomes}

The current analysis aimed to investigate the impact of the type of mutated gene (BRCA1 vs. BRCA2) and hormone receptor status on clinical 
behavior and outcomes of young breast cancer patients with germline $B R C A$ pathogenic variants.

Clinicopathological characteristics, pattern, and risk over time of diseasefree survival (DFS) events, as well as prognosis (in terms of DFS, distant recurrence-free interval [DRFI], and overall survival [OS]) were compared between the BRCA1 and BRCA2 cohorts. The same analyses comparing the $B R C A 1$ and $B R C A 2$ cohorts were then performed separately in patients with hormone receptor-positive and negative disease.

To specifically assess the effect of hormone receptor status, clinicopathological characteristics, pattern, and risk over time of DFS events, as well as prognosis (in terms of DFS, DRFI, and OS) were compared between patients with hormone receptor-positive and negative disease irrespective of the type of mutated gene.

\section{Statistical analysis}

Descriptive analyses were used to assess clinicopathological characteristics as well as the pattern of DFS events.

To assess the risk of developing DFS events over time, the Epanechnikov Kernel-Smoothed annual hazards of recurrence were calculated.

DFS was defined as the time from diagnosis until the first appearance of one of the following invasive events: loco-regional recurrence, distant metastases, new contralateral or ipsilateral breast cancer, second primary malignancy, or death from any cause. DRFI was calculated as the time from diagnosis until the first occurrence of invasive breast cancer recurrence at a distant site. OS was defined as the time from diagnosis until death from any cause.

Observation times of patients that did not experience an event were censored on the date of their last contact. Kaplan-Meier plots were used to present results with a follow-up time of up to 10 years. Cox proportional hazard model was applied to estimate the hazard ratios (HRs) over the whole follow-up period, adjusting for the concomitant effect of selected confounders. Multivariate models for all survival analyses included nodal status, grade, HER2, type of breast surgery, chemotherapy use, age, year of diagnosis, and country.

Homogeneity tests on the HRs were performed in all survival analyses using the likelihood ratio test to assess whether there was evidence of an interaction between the type of gene and hormone receptor status.

All statistical analyses were two-sided; $P$ values $<0.05$ were considered as statistically significant. Statistical analyses were performed by $M C$ and MB using Stata 13.1 (StataCorp. 2013. Stata Statistical Software: Release 13. College Station, TX: StataCorp LP).

\section{Reporting summary}

Further information on research design is available in the Nature Research Reporting Summary linked to this article.

\section{DATA AVAILABILITY}

The data generated and analysed during this study are described in the following data record: https://doi.org/10.6084/m9.figshare.13507422 $2^{41}$. The data are stored in the following four Excel spreadsheets: 'Patient survival data.xlsx', 'Patient baseline, tumor and treatment data.xlsx', 'Patient risk-reducing surgery data.xlsx', 'Patient eligibility criteria and survival data.xlsx'. These data are not publicly available for the following reason: data contain information that could compromise research participant privacy. However, the data can be made available upon reasonable request to the corresponding author. A list of which data file underlies which figure, table, and supplementary table in the related manuscript is provided in the file 'Lambertini et al. underlying data lookup.csv', included as part of the metadata record $^{41}$. The dataset analysed during this study is described with more details in the following manuscript: https://doi.org/10.1200/JCO.19.02399 ${ }^{39}$.

Received: 15 September 2020; Accepted: 7 January 2021; Published online: 12 February 2021

\section{REFERENCES}

1. Fidler, M. M. et al. Cancer incidence and mortality among young adults aged 2039 years worldwide in 2012: a population-based study. Lancet Oncol. 18, 1579-1589 (2017).

2. Azim, H. A. \& Partridge, A. H. Biology of breast cancer in young women. Breast Cancer Res. 16, 427 (2014).
3. Partridge, A. H. et al. Subtype-dependent relationship between young age at diagnosis and breast cancer survival. J. Clin. Oncol. 34, 3308-3314 (2016).

4. Paluch-Shimon, S. et al. ESO-ESMO 4th International Consensus Guidelines for Breast Cancer in Young Women (BCY4). Ann. Oncol. 31, 674-696 (2020).

5. Rosenberg, S. M. et al. BRCA1 and BRCA2 mutation testing in young women with breast cancer. JAMA Oncol. 2, 730-736 (2016).

6. Copson, E. R. et al. Germline BRCA mutation and outcome in young-onset breast cancer (POSH): a prospective cohort study. Lancet Oncol. 19, 169-180 (2018).

7. Paluch-Shimon, S. et al. Prevention and screening in BRCA mutation carriers and other breast/ovarian hereditary cancer syndromes: ESMO Clinical Practice Guidelines for cancer prevention and screening. Ann. Oncol. 27, v103-v110 (2016).

8. Tung, N. M. et al. Management of Hereditary Breast Cancer: American Society of Clinical Oncology, American Society for Radiation Oncology, and Society of Surgical Oncology Guideline. J. Clin. Oncol. 38, 2080-2106 (2020).

9. Eerola, H. et al. Histopathological features of breast tumours in BRCA1, BRCA2 and mutation-negative breast cancer families. Breast Cancer Res. 7, R93-R100 (2005).

10. Atchley, D. P. et al. Clinical and pathologic characteristics of patients with BRCApositive and BRCA-negative breast cancer. J. Clin. Oncol. 26, 4282-4288 (2008).

11. Goodwin, P. J. et al. Breast cancer prognosis in BRCA1 and BRCA2 mutation carriers: an International Prospective Breast Cancer Family Registry populationbased cohort study. J. Clin. Oncol. 30, 19-26 (2012).

12. Spurdle, A. B. et al. Refined histopathological predictors of BRCA1 and BRCA2 mutation status: a large-scale analysis of breast cancer characteristics from the BCAC, CIMBA, and ENIGMA consortia. Breast Cancer Res. 16, 3419 (2014).

13. van den Broek, A. J., Schmidt, M. K., van't Veer, L. J., Tollenaar, R. A. E. M. \& van Leeuwen, F. E. Worse breast cancer prognosis of BRCA1/BRCA2 mutation carriers: what's the evidence? A systematic review with meta-analysis. PLOS ONE 10, e0120189 (2015).

14. Evans, D. G. et al. Low prevalence of HER2 positivity amongst BRCA1 and BRCA2 mutation carriers and in primary BRCA screens. Breast Cancer Res. Treat. 155, 597-601 (2016).

15. Vocka, M. et al. Estrogen receptor status oppositely modifies breast cancer prognosis in BRCA1/BRCA2 mutation carriers versus non-carriers. Cancers 11, 738 (2019).

16. Jonasson, J. G. et al. Oestrogen receptor status, treatment and breast cancer prognosis in Icelandic BRCA2 mutation carriers. Br. J. Cancer 115, 776-783 (2016).

17. Schmidt, M. K. et al. Breast cancer survival of BRCA1/BRCA2 mutation carriers in a hospital-based cohort of young women. J. Natl. Cancer Inst. 109 (2017).

18. Metcalfe, K. et al. Oestrogen receptor status and survival in women with BRCA2associated breast cancer. Br. J. Cancer 120, 398-403 (2019).

19. Kuchenbaecker, K. B. et al. Risks of breast, ovarian, and contralateral breast cancer for BRCA1 and BRCA2 mutation carriers. JAMA 317, 2402-2416 (2017).

20. Mavaddat, N. et al. Cancer risks for BRCA1 and BRCA2 mutation carriers: results from prospective analysis of EMBRACE. J. Natl. Cancer Inst. 105, 812-822 (2013).

21. Graeser, M. K. et al. Contralateral breast cancer risk in BRCA1 and BRCA2 mutation carriers. J. Clin. Oncol. 27, 5887-5892 (2009).

22. Berkowitz, Z., Rim, S. H. \& Peipins, L. A. Characteristics and survival associated with ovarian cancer diagnosed as first cancer and ovarian cancer diagnosed subsequent to a previous cancer. Cancer Epidemiol. 35, 112-119 (2011).

23. van den Broek, A. J. et al. Impact of age at primary breast cancer on contralateral breast cancer risk in BRCA1/2 mutation carriers. J. Clin. Oncol. 34, 409-418 (2016).

24. Hartmann, L. C. \& Lindor, N. M. The role of risk-reducing surgery in hereditary breast and ovarian cancer. N. Engl. J. Med. 374, 454-468 (2016).

25. Dullens, B. et al. Cancer Surveillance in Healthy Carriers of Germline Pathogenic Variants in BRCA1/2: A Review of Secondary Prevention Guidelines. J. Oncol. 9873954 (2020).

26. Baek, H. J. et al. Inhibition of Estrogen Signaling Reduces the Incidence of BRCA1associated Mammary Tumor Formation. Int. J. Biol. Sci. 14, 1755-1768 (2018).

27. Wang, C. et al. Estrogen promotes estrogen receptor negative BRCA1-deficient tumor initiation and progression. Breast Cancer Res. 20, 74 (2018).

28. Tung, N. et al. Estrogen receptor positive breast cancers in BRCA1 mutation carriers: clinical risk factors and pathologic features. Breast Cancer Res. 12, R12 (2010).

29. Lips, E. H. et al. BRCA1-mutated estrogen receptor-positive breast cancer shows BRCAness, suggesting sensitivity to drugs targeting homologous recombination deficiency. Clin. Cancer Res. 23, 1236-1241 (2017).

30. Lewin, R. et al. Oncotype-DX recurrence score distribution in breast cancer patients with BRCA1/2 mutations. Breast Cancer Res. Treat. 157, 511-516 (2016).

31. Shah, P. D. et al. Twenty-one-gene recurrence score assay in BRCA-associated versus sporadic breast cancers: differences based on germline mutation status. Cancer 122, 1178-1184 (2016).

32. Halpern, N. et al. Oncotype Dx recurrence score among BRCA1/2 germline mutation carriers with hormone receptors positive breast cancer. Int. J. Cancer 140, 2145-2149 (2017). 
33. Huzarski, T. et al. Ten-year survival in patients with BRCA1-negative and BRCA1positive breast cancer. J. Clin. Oncol. 31, 3191-3196 (2013).

34. Jiang, T. et al. Predictors of chemosensitivity in triple negative breast cancer: an integrated genomic analysis. PLoS Med. 13, e1002193 (2016).

35. Tung, N. et al. TBCRC 031: Randomized phase II study of neoadjuvant cisplatin versus doxorubicin-cyclophosphamide in germline BRCA carriers with HER2negative breast cancer (the INFORM trial). J. Clin. Oncol. 38, 1539-1548 (2020).

36. Lambertini, M., Blondeaux, E., Perrone, F., Del \& Mastro, L. Improving adjuvant endocrine treatment tailoring in premenopausal women with hormone receptorpositive breast cancer. J. Clin. Oncol. 38, 1258-1267 (2020).

37. Burstein, H. J. et al. Adjuvant Endocrine Therapy for Women With Hormone ReceptorPositive Breast Cancer: American Society of Clinical Oncology Clinical Practice Guideline Update on Ovarian Suppression. J. Clin. Oncol. 34, 1689-1701 (2016).

38. Burstein, H. J. et al. Adjuvant Endocrine Therapy for Women With Hormone Receptor-Positive Breast Cancer: ASCO Clinical Practice Guideline Focused Update. J. Clin. Oncol. 37, 423-438 (2019).

39. Lambertini, M. et al. Pregnancy after breast cancer in patients with germline BRCA mutations. J. Clin. Oncol. 38, 3012-3023 (2020).

40. von Elm, E. et al. The Strengthening the Reporting of Observational Studies in Epidemiology (STROBE) statement: guidelines for reporting observational studies. Lancet 370, 1453-1457 (2007).

41. Lambertini, M. et al. Metadata record for the manuscript: clinical behavior and outcomes of breast cancer in young women with germline BRCA pathogenic variants. figshare https://doi.org/10.6084/m9.figshare.13507422 (2020).

\section{ACKNOWLEDGEMENTS}

This study received partial financial support by grants from the Italian Ministry of Health $5 \times 1000$ funds 2017 (no grant number), the Italian Association for Cancer Research (AIRC; MFAG 2020 ID 24698), and "Les Amis de l'Institut Bordet" foundation (no grant number). The funders had no role in the design and conduct of the study; collection, management, analysis, and interpretation of the data; preparation, review, or approval of the manuscript; and decision to submit the manuscript for publication. M.L. acknowledges the support from the European Society for Medical Oncology (ESMO) for a Translational Research Fellowship at the Institut Jules Bordet in Brussels (Belgium) at the time of study conduction. K.P. acknowledges the support from a predoctoral clinical 'KOOR' mandate from the University Hospitals Leuven (Leuven, Belgium). F.P.D. acknowledges the support for a postdoctoral clinical mandate (2017-034) from the not-for-profit organization 'Foundation Against Cancer' (Brussels, Belgium). A.H.P. acknowledges the support from Susan G. Komen and Breast Cancer Research Foundation (BCRF). J.H. acknowledges the support from the Carlos III National Health Institute funded by FEDER funds-a way to build Europe (PI16/11363). This research was presented in the Poster Spotlight session at the 2020 San Antonio Breast Cancer Symposium (SABCS), San Antonio, TX, United States of America, on 8-12 December 2020.

\section{AUTHOR CONTRIBUTIONS}

Concept and design: M.L. and H.A.A. Jr. Acquisition, analysis, or interpretation of data: M.L., M.C., A.S.H., O.C., P.D.P., E.C., A.G., K.P., C.R.J., A.F., S.P.S, A.T., C.S., F.P., K.P., J.A.P.F., L.D.M., R.P., L.L., M.D.P.E.D., C.V.G., M.V.D., F.C., F.P.D., R.G., L.T, O.C., A.S, A.R.F., A.H.P., A D.M., C.S., F.A.P., M.B, L.A., M.D.T.K.D.R., J.B., L.D.M. and H.A.A. Jr. Drafting of the manuscript: M.L. Critical revision of the manuscript for important intellectual content: M.C., A.S.H., O.C., P.D.P., E.C., A.G., K.P., C.R.J., A.F., S.P.S, A.T., C.S., F.P., K.P., J.A.P.F., L.D. M., R.P., L.L., M.D.P.E.D., C.V.G., M.V.D., F.C., F.P.D., R.G., L.T, O.C., A.S, A.R.F., A.H.P., A.D. M, C.S., F.A.P., M.B, L.A., M.D.T.K.D.R., J.B., L.D.M. and H.A.A. Jr. Statistical analysis: M.C., M.B. Administrative, technical, or material support: M.L., M.C., A.S.H., O.C., P.D.P., E.C., A.G., K.P., C.R.J., A.F., S.P.S, A.T., C.S., F.P., K.P., J.A.P.F., L.D.M., R.P., L.L., M.D.P.E.D., C.V.G., M.V.D., F.C., F.P.D., R.G., L.T, O.C., A.S, A.R.F., A.H.P., A.D.M, C.S., F.A.P., M.B, L.A., M.D.T.K D.R., J.B., L.D.M. and H.A.A. Jr. Final approval of the completed version: M.L., M.C., A.S. H., O.C., P.D.P., E.C., A.G., K.P., C.R.J., A.F., S.P.S, A.T., C.S., F.P., K.P., J.A.P.F., L.D.M., R.P., L. L., M.D.P.E.D., C.V.G., M.V.D., F.C., F.P.D., R.G., L.T, O.C., A.S, A.R.F., A.H.P., A.D.M, C.S., F.A P., M.B, L.A., M.D.T.K.D.R., J.B., L.D.M. and H.A.A. Jr. Accountability for all aspects of the work: M.L., M.C., A.S.H., O.C., P.D.P., E.C., A.G., K.P., C.R.J., A.F., S.P.S, A.T., C.S., F.P., K.P., J. A.P.F., L.D.M., R.P., L.L., M.D.P.E.D., C.V.G., M.V.D., F.C., F.P.D., R.G., L.T, O.C., A.S, A.R.F., A H.P., A.D.M, C.S., F.A.P., M.B, L.A., M.D.T.K.D.R., J.B., L.D.M. and H.A.A. Jr.

\section{COMPETING INTERESTS}

M.L. acted as a consultant for Roche, AstraZeneca, Lilly and Novartis, and received honoraria from Sandoz, Roche, Novartis, Takeda, Pfizer and Lilly outside the submitted work. O.C. acted as a consultant for AstraZeneca, and received travel grants from Ipsen outside the submitted work. C.R.J. acted as a consultant for Mylan medical, and received honoraria from Theramex and Bayer outside the submitted work. F.P. acted as a consultant for Astrazeneca, Daichii Sankyo, MSD, Novartis, Pierre Fabre, and Roche, received honoraria from Lilly, Novartis, Pfizer, Roche and Takeda, and received research grants from Astrazeneca, EISAI, and Roche outside the submitted work. K.P. acted as a consultant, received speaker honoraria and travel grants from Roche, Novartis, Pfizer, AstraZeneca, Lilly, Pierre Fabre, Egis, Amgen, Angelini and Teva outside the submitted work. J.A.P.F. acted as a consultant for Amgem, Astrazeneca, Clovis, and G.S.K., received honoraria from Roche, Astrazeneca, Novartis, Clovis, and G.S.K. and travel expenses by Roche, Astrazeneca, Pfizer, and G.S.K. outside the submitted work. C.V.G. acted as a consultant for Pfizer, Roche, Novartis, and Lilly, received honoraria from Myriad Genetics, Roche and Novartis, research funding from Roche and AstraZeneca, and travel expenses by Roche, MSD Oncology and Pfizer outside the submitted work. F. C. acted as a consultant for Lilly, BMS and Roche, received speaker honoraria from Merck Serono and BMS, research funding to his institution from AstraZeneca, and travel grants from Roche, Merck Serono, and BMS outside the submitted work. F.P. D. acted as a consultant for Roche, Pfizer, AstraZeneca, Lilly, Amgen, Novartis, Pierre Fabre, and Daiichi Sankyo, and received travel grants from Roche, Pfizer, Teva, and Amgen outside the submitted work. L.T. acted as a consultant for AstraZeneca, Lilly, Novartis, Pfizer, and Roche, received speaker honoraria from AstraZeneca, Merck Serono, Lilly, Novartis, Roche, research funding to his institution from Pfizer and Novartis, and travel grants from Roche, Merck Serono, and AstraZeneca, Novartis and Roche outside the submitted work. A.S. acted as a consultant for Novartis, Roche, Pfizer, and Lilly, received speaker honoraria from Roche, Pfizer, Medison, Lilly, and Novartis, research funding from Novartis, and travel grants from Medison and Roche outside the submitted work. A.R.F. received travel grants from Novartis and Roche outside the submitted work. A.D.M. received honoraria from ThermoFisher outside of the submitted work. J.B. acted as a consultant and received travel grants from Pfizer and Astra Zeneca outside the submitted work. L.D.M. acted as a consultant for Roche, Novartis, MSD, Pfizer, Ipsen, AstraZeneca, Genomic Health, Lilly, Seattle Genetics, Eisai, Pierre Fabre, and Daiichi Sankyo, received speaker honoraria from Roche, Novartis, Lilly and MSD, and travel grants from Roche, Pfizer and Celgene outside the submitted work. H.A A. Jr acted as a consultant for Roche, received honoraria from Novartis outside the submitted work, and reported employment at Innate Pharma at the end of this study; this employment is not related in any sort to the subject of the current study. All the other authors declare no competing interests.

\section{ADDITIONAL INFORMATION}

Supplementary information The online version contains supplementary material available at https://doi.org/10.1038/s41523-021-00224-w.

Correspondence and requests for materials should be addressed to M.L.

Reprints and permission information is available at http://www.nature.com/ reprints

Publisher's note Springer Nature remains neutral with regard to jurisdictional claims in published maps and institutional affiliations.

\begin{abstract}
Open Access This article is licensed under a Creative Commons Attribution 4.0 International License, which permits use, sharing, adaptation, distribution and reproduction in any medium or format, as long as you give appropriate credit to the original author(s) and the source, provide a link to the Creative Commons license, and indicate if changes were made. The images or other third party material in this article are included in the article's Creative Commons license, unless indicated otherwise in a credit line to the material. If material is not included in the article's Creative Commons license and your intended use is not permitted by statutory regulation or exceeds the permitted use, you will need to obtain permission directly from the copyright holder. To view a copy of this license, visit http://creativecommons. org/licenses/by/4.0/.
\end{abstract}

C The Author(s) 2021 